\title{
DEVELOPMENT OF PILOT PLANT FOR BIO-ETHANOL PROCESSING
}

\author{
Emrod Elisante \\ Department of Chemical and Mining Engineering, University of Dar es \\ Salaam \\ P. O. Box 35131 Dar es Salaam, Tanzania \\ elisante@udsm.ac.tz, Tel: +255-754-865695
}

\begin{abstract}
The paper outlines achievements obtained in developing a pilot bio-ethanol plant at the Department of Chemical and Mining Engineering (CME), University of Dar es Salaam. The pilot plant consists of: $30 \mathrm{~L}$ inoculums tank; 1,700 L fermenter; 1,500 L/day distillation column; and ancillary equipment. The prototype is a platform intended to be used for technology demonstration and research by graduate and undergraduate students studying the production of bio-ethanol using traditional and non-traditional raw materials like coffee mash, cashew fruit, and sisal inulin. The equipment has been developed using locally available engineering resources and the distillation column with 18 sieve tray measures 0.5 $m$ diameter $7 \mathrm{~m}$ high operates at atmospheric pressure. The condenser is cooled by $15{ }^{\circ} \mathrm{C}$ chilled water from utility lines and the reboiler is powered by $63 \mathrm{~kW}$ boiler installed at CME. Although the system includes biological, chemical and mechanical engineering details, only the important design issues are presented. A MATLAB code was developed for estimating the number of theoretical plates using the Mc Cabe-Thiele method. The waterethanol vapour liquid equilibrium VLE data was obtained using relative volatilities estimated by Antoine equations for vapour pressure. The process design was done using various simulation packages and custom programs like Microsoft Excel for mass balance, Microsoft Visio for process and instrumentation (P\&I) diagram AutoCAD software for mechanical engineering drawings. After performing hydraulic leak tests, the prototype was tested using blackstrap molasses $80^{\circ}$ brix which was prepared for fermentation using dilution and inoculums formulations developed in Microsoft Excel for water dilution, yeast and nutrients like $\left(\mathrm{NH}_{4}\right)_{2} \mathrm{SO}_{4}, \mathrm{KH}_{2} \mathrm{PO}_{4}, \mathrm{MgCl}_{2}$. A batch mash boiling test conducted on the column showed that the response of tray temperatures exhibited first-order delay behavior with an average lag of 17 minutes and a delay of 50 -65 minutes depending on tray distance from the reboiler. Due to lack of feedback control equipment specifically on-line composition analyzers and suitable actuators, continuous control of ethanol composition could not be undertaken. It is planned to procure pertinent control hardware during the next phase of the project. However the batch test gave initial ethanol purity of $80 \%$ which decreased as the ethanol content in the still was continuously depleted.
\end{abstract}

\section{INTRODUCTION}

\section{Literature Review}

Tanzania like many developing countries imports ethanol for domestic and industrial uses despite ample availability of bio-ethanol agricultural raw materials like sugarcane, molasses, cashew apple, banana and coffee mash. For instance, most of the molasses produced from large-scale sugar mills shown in Figure 1
Kilombero Sugar Company (KSC); Mtibwa Sugar Estates (MSE); and Tanganyika Planting Company TPC, is exported and the rest is used for animal feed or de-dusting roads (Lukyaa, 1998). Apart from excess molasses from largesugar plants, Tanzania has more than 134 potential sites (Katalambula et al., 1996) for cultivation of sugarcane, which can be directly or indirectly processed to bioethanol. The main problem is availability of affordable and simple technologies 
adaptable for ethanol production in rural areas. At present there are only two medium-scale distilleries which import crude ethanol then blend it to produce

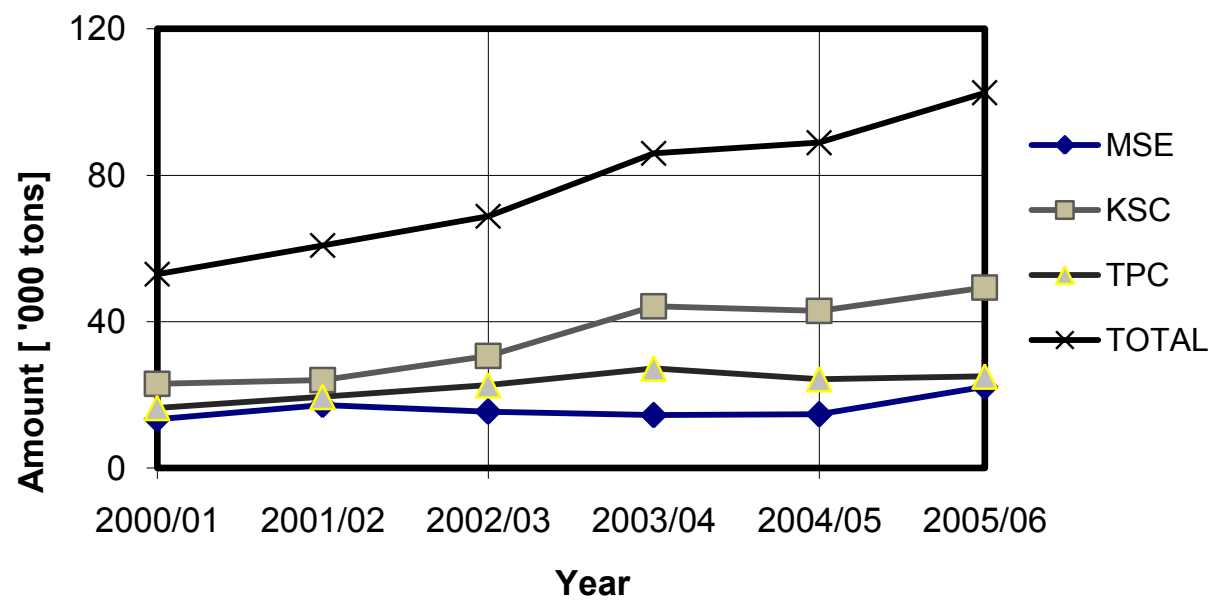

Figure 1: Production of Molasses by Large-scale Sugar Mills in Tanzania (Source: SDC, 2008)

alcoholic beverages. The technology for medium- and large-scale production is available on turn-key but is expensive hence unaffordable by local entrepreneurs. For example, a plant producing 30,000 L/day costs about US\$ 2.2 million excluding know-how and

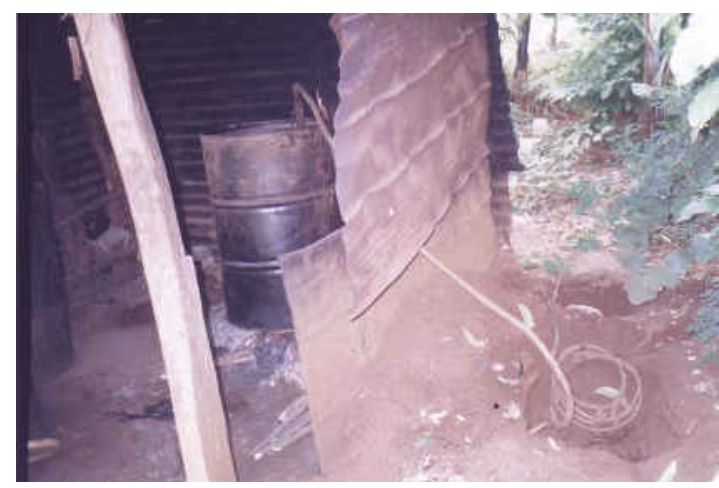

Figure 2: Batch Distillation Equipment Used by Small-scale Entrepreneurs

The alcohol produced by unlicensed entrepreneurs pose a number of risks including, safety, health, environmental and socio-economic like:

(i) Explosion of molasses tanks (Hatibu, 2007) during batch distillation which often result in injury of operators;

(ii) Tainting of ethanol by unwanted fermentation by-products like aldehydes, ketones or methanol technology transfer fees (APCTT, 2003). Due to high capital and technology fees, unlicensed entrepreneurs use crude equipment (Figure. 2) to process illicit alcoholic drinks which they sell under different names gongo, chang'aa or moonshine.

(Mosha et al., 1996), which cause blindness or death;

(iii) Land pollution and ground water contamination by aldehydes and fusel oils;

(iv) Loss of tax revenue through unofficial transactions;

(v) Manpower loss due to general body malaise caused by alcoholism.

Recognizing the technological needs and limitations to get a practical solution, the University of Dar es Salaam, since 1984 engaged on R\&D work aimed at developing, testing, and commercializing small-scale ethanol processing technology. In the 1980s the former Institute of Production Innovation (IPI) made several attempts to develop pilot distillation equipment as shown in Table 1. Unfortunately the equipment had design problems which could not be rectified and the throughput was very low (36-120 L/day) for commercial viability. 
Table 1: Distillation Units Developed by IPI (Source: Kaunde, 1993)

\begin{tabular}{|l|c|c|c|c|}
\hline & 1983 & 1984 & 1987 & 1989 \\
\hline $\begin{array}{l}\text { Operation } \\
\text { Mode }\end{array}$ & Batch & $\begin{array}{l}\text { Conti } \\
\text { nuou } \\
\mathrm{s}\end{array}$ & $\begin{array}{c}\text { Conti } \\
\text { nuou } \\
\mathrm{s}\end{array}$ & $\begin{array}{c}\text { Conti } \\
\text { nuous }\end{array}$ \\
\hline Power [kW] & 1.5 & 1.5 & 2 & 1.5 \\
\hline Tray type & Baffle & $\begin{array}{c}\text { Baffl } \\
\mathrm{e}\end{array}$ & Sieve & $\begin{array}{c}\text { Baffl } \\
\mathrm{e}\end{array}$ \\
\hline $\begin{array}{l}\text { Throughput } \\
\text { [L/hr] }\end{array}$ & 1.5 & 1.5 & 5 & 1.5 \\
\hline Purity [\%] & 92 & 80 & 85 & 95 \\
\hline
\end{tabular}

From 1990s there had been renewed interest on bio-ethanol by researchers at the Department of Chemical and Process Engineering (CPE). Temu and Mbagga (1993) established optimal fermentation parameters like, temperature, $\mathrm{pH}$, nutrients, yeast inoculums, and initial sugar concentrations. Kibazohi (2003) and Msemwa (2008) conducted studies aimed at production of citric acid and ethanol respectively from sisal inulin. Haule (2009) proposed a dry method for characterization, hydrolysis and fermentation of bitter cassava variety grown in Tanzania for production of ethanol. This work aims at consolidating the $R \& D$ effort and experiences obtained by the above scholars by developing a 1,500 L/day ethanol pilot plant at the University of Dar es Salaam for testing and validating their works. Specifically the objective is to develop a commercially viable technology that utilizes local resources but meets national and international standards in terms of product purity and safety.

\section{METHODOLOGY}

Only the major design issues related to development of the technology are included here. Detail design of mechanical and chemical engineering aspects including physical properties and theoretical design of the fermenter, column and ancillary equipment are given in Elisante (2007).

\section{Process Design}

The process and instrumentation $(\mathrm{P} \& \mathrm{I})$ diagram is shown in Figure. 3. Due to

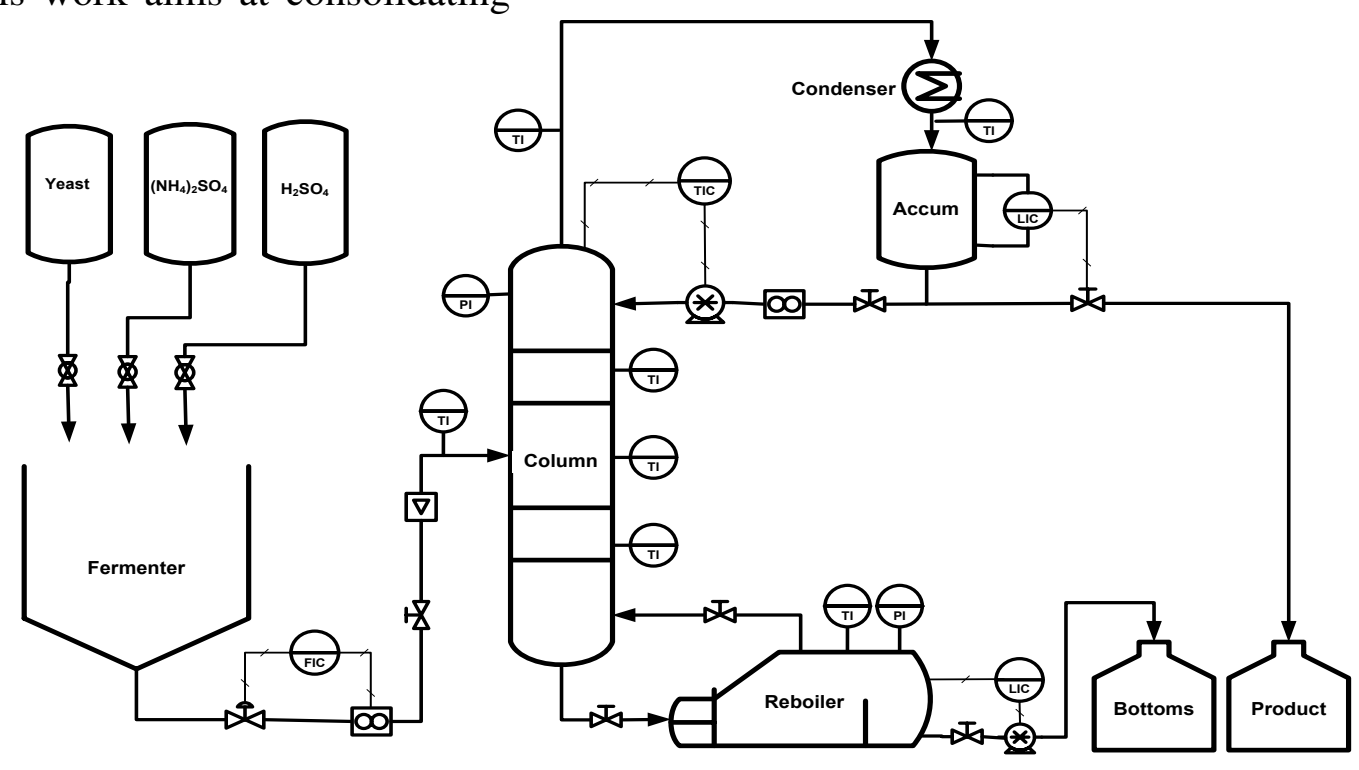

Figure 3: Process and Instrumentation Diagram for Ethanol Processing 


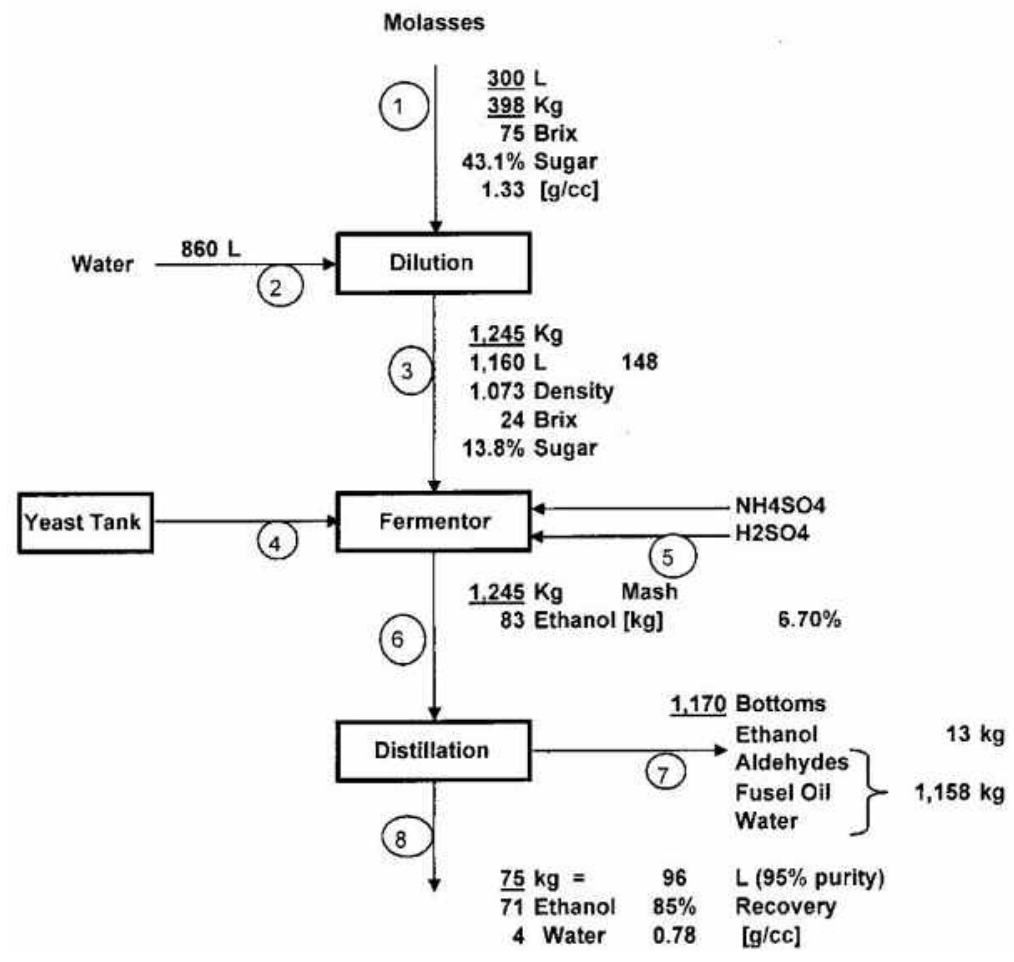

Figure 4: Mass Balance Simulation

corrosive nature of molasses and hygienic requirement for the product, the material specification for vessels and pipes carrying mash or ethanol is stainless steel SS 316. The pilot plant was designed to produce 1,500 litres of ethanol per day and mass balance simulation for the process was programmed using the Microsoft Excel software as shown in Figure. 4.

\section{Number of Stages and Column Internals}

The determination of number of stages was done using the McCabe-Thiele method (Coulson and Richardson, 1993) from vapor liquid equilibrium (VLE) curve. Usually the VLE is obtained experimentally but in this work it was generated from theoretical vapor-liquid equilibrium relationship:

$$
\mathrm{y}_{\mathrm{n}}=\frac{\alpha \mathrm{x}_{\mathrm{n}}}{1+(\alpha-1) \mathrm{x}_{\mathrm{n}}}
$$

Where $\alpha$ is the relative volatility of ethanol compared to water at a fixed temperature $\alpha(\mathrm{T})=\mathrm{P}_{\mathrm{C}_{2} \mathrm{H}_{5} \mathrm{OH}}^{\text {sat }} / \mathrm{P}_{\mathrm{H}_{5} \mathrm{O}}^{\text {sat }}$ and $\mathrm{P}_{\mathrm{i}}^{\text {sat }}$ is saturation vapour pressure estimated using the Antoine equation:

$$
\ln \mathrm{P}_{\mathrm{i}}^{\mathrm{sat}}=\mathrm{A}_{\mathrm{i}}-\mathrm{B}_{\mathrm{i}} /\left(\mathrm{T}+\mathrm{C}_{\mathrm{i}}\right)
$$

in which $A_{i}, B_{i}$, and $C_{i}$ are respective Antoine constants for a particular species. A MATLAB program EtOHH2OEquilPlot.m was developed to simplify determination of number of stages using the Mc Cabe-Thiele method from the equilibrium curve as shown in Figure. 5. Assuming a feed $7 \%$ (wt/wt) enters the $5^{\text {th }}$ tray at room temperature, a total of 11 stages were obtained with the reboiler counted as first stage. Using a Murphee efficiency of $60 \%$, the actual number of plates obtained was 11/0.6 = 18 stages. 


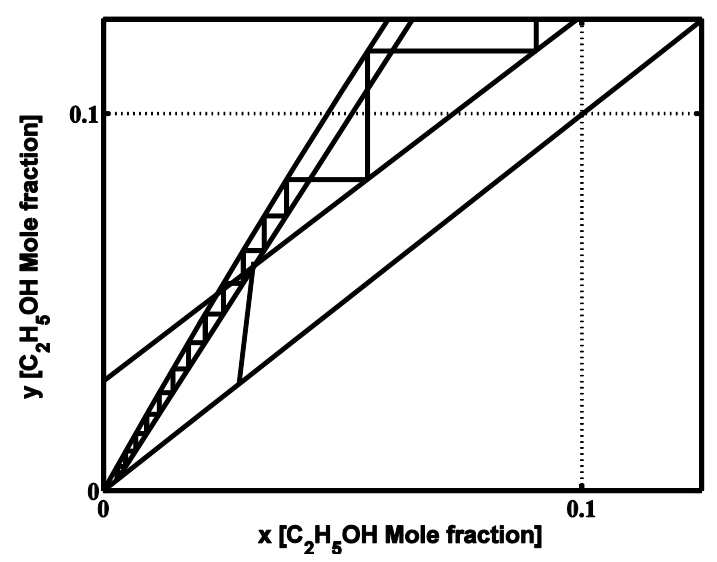

Figure 5: Determination of Number Stages Using McCabe-Thiele Method

The column diameter was estimated using the correlations established by Fair (1961). A column diameter of $0.5 \mathrm{~m}$ was obtained based on a design assumption that the column must accommodate $80 \%$ of the flooding velocity and the tray spacing is $0.305 \mathrm{~m}$. For a total of 18 stages this gave an overall column height of the $6.9 \mathrm{~m}$ with the feed and first trays having a height of $450 \mathrm{~mm}$.
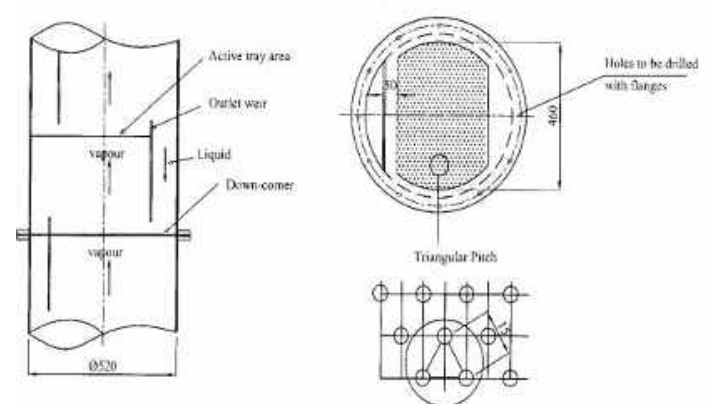

Figure 6: Details of Column Internal Design and Sieve Trays

In order to minimize cost, a sieve tray made from $5 \mathrm{~mm}$ aluminum sheet with a $15 \mathrm{~mm}$ triangular pitch was chosen. The design of column internals like weir height and sieve perforations shown in Figure. 6 was done using a procedure outlined in Coulson and Richardson (1993).

\section{Yeast Inoculation and Fermentation}

Due to budget and space limitations, a rectangular fermentation tank $1,700 \mathrm{~L}$ was designed to provide sufficient quantity for 4-6 hours continuous feed to column. The fermenter is equipped with 1.5 inch coils with a total heat transfer area of $6 \mathrm{~m}^{2}$ and a stirrer $1.25 \mathrm{~kW}$ rotating at $40 \mathrm{rpm}$ to enhance heat transfer during steam sterilization or cooling during fermentation. A $30 \mathrm{~L}$ tank was fabricated (Figure. 7) for preparation of inoculums. The tank is fitted with: air sterilization chamber; glass wool moisture drier; and a water bath for temperature control. Prior to fermentation yeast inoculums is prepared using a small amount of molasses, yeast- Saccharomyces cervisae, and pertinent nutrients whilst oxygen is supplied from compressed air line bubbled through the sterilization chamber , which is filled with concentrated sulphuric acid.

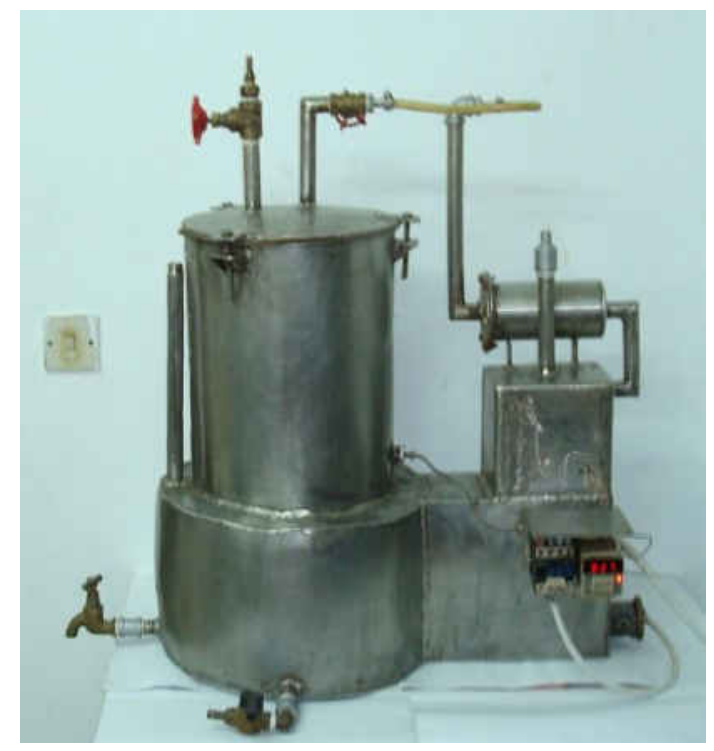

Figure 7: Inoculums Tank

The inoculums recipe proposed by Temu and Mbagga (1993) was used and a MsExcel program inocul_prep.xlsx was developed for computing volumes, weight, brix and sugar percent for any mix volume required as shown in Table 2 . 
Table 2: Inoculums Preparation Schedule

\begin{tabular}{|c|c|c|}
\hline Description & Amount & Recommended values/remarks \\
\hline \multicolumn{3}{|l|}{ Molasses feed batch } \\
\hline Total volume & $300 \mathrm{~L}$ & \\
\hline Total weight & $398 \mathrm{~kg}$ & \\
\hline Feed brix & $75[\mathrm{w} / \mathrm{w} \%]$ & \\
\hline Density & $1.33 \mathrm{~g} / \mathrm{cc}$ & \\
\hline Sugar percent $[\mathrm{w} / \mathrm{w}]$ & $43.1[\mathrm{w} / \mathrm{w} \%]$ & \\
\hline \multicolumn{3}{|l|}{ Inoculums preparation } \\
\hline Molasses specification & & Sugar:20\%, Brix:35, Density: 1.1269 \\
\hline Total yeast required per batch & $430 \mathrm{~g}$ & 0.0025 yeast/initial sugar $[\mathrm{g} / \mathrm{g}]$ \\
\hline Yeast dose for Inoculums & & 20 g per $1000 \mathrm{cc}$, Molasses- $20 \%$ sugar \\
\hline Molasses required & $11.24 \mathrm{~kg}$ & $8.5 \mathrm{~L}$ \\
\hline Water required for dilution & $12.99 \mathrm{~kg}$ & $13 \mathrm{~L}$ \\
\hline Total inoculums & $24.23 \mathrm{~kg}$ & $21.5 \mathrm{~L}$ \\
\hline \multicolumn{3}{|l|}{ Nutrients } \\
\hline$\left(\mathrm{NH}_{4}\right)_{2} \mathrm{SO}_{4}$ & $5.38 \mathrm{~g}$ & $0.25 \mathrm{~g} / \mathrm{L}$ \\
\hline $\mathrm{KH}_{2} \mathrm{PO}_{4}$ & $2.15 \mathrm{~g}$ & $0.10 \mathrm{~g} / \mathrm{L}$ \\
\hline $\mathrm{MgCl}_{2}$ & $0.65 \mathrm{~g}$ & $0.03 \mathrm{~g} / \mathrm{L}$ \\
\hline $\mathrm{CaCl}_{2}$ & $0.43 \mathrm{~g}$ & $0.02 \mathrm{~g} / \mathrm{L}$ \\
\hline $\mathrm{NaCl}$ & $0.65 \mathrm{~g}$ & $0.03 \mathrm{~g} / \mathrm{L}$ \\
\hline $\mathrm{FeCl}_{3}$ & $0.15 \mathrm{~g}$ & $0.01 \mathrm{~g} / \mathrm{L}$ \\
\hline
\end{tabular}

\section{Control and Instrumentation}

The most important parameters to be controlled in distillation systems include: (i) composition of product $\mathrm{x}_{\mathrm{D}}$ and bottoms $\mathrm{x}_{\mathrm{B}}$; (ii) feed flow rate $\mathrm{F}$; and (iii) levels in the reboiler and reflux tanks. Because measurement of on-line bottoms and top compositions is expensive and difficult to implement using a gas chromatography (GC), a simple refractometer with capability to take brix measurement simultaneously was used. The temperature of all trays $1^{\text {st }}$ to $18^{\text {th }}$ was monitored by multi-point temperature recorder Model Comark M 711621. A peristaltic Masterflex pump Model No. 7521-25 with RS 232 port was used to control level of the accumulator. General temperature data was logged using 14 bit National Instrument LabView card NI USB-6009 Model No. 191039D-01L and interfaced with 8 type $\mathrm{K}$ thermocouples.
The bio-ethanol pilot plant, which compose of inoculums tank, fermenter and distillation column was designed, manufactured and erected at the Department of Chemical and Mining Engineering of the University of Dar es Salaam as shown in Figs. 9 and 10.

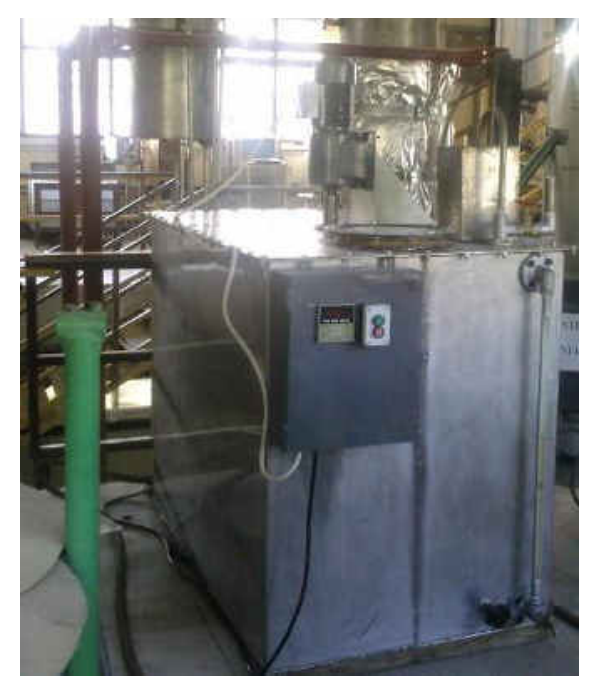

Figure 9: Fermentation Vessel

\section{RESULTS AND DISCUSSIONS}


Simple hydraulic tests like leak detection and water boiling were conducted prior to production of ethanol using blackstrap molasses of 80 Brix from Kilombero Sugar Company. Thirty litres of inoculums were prepared as described in Table 2 then added into the batch fermenter 1,700 L into which pre-diluted

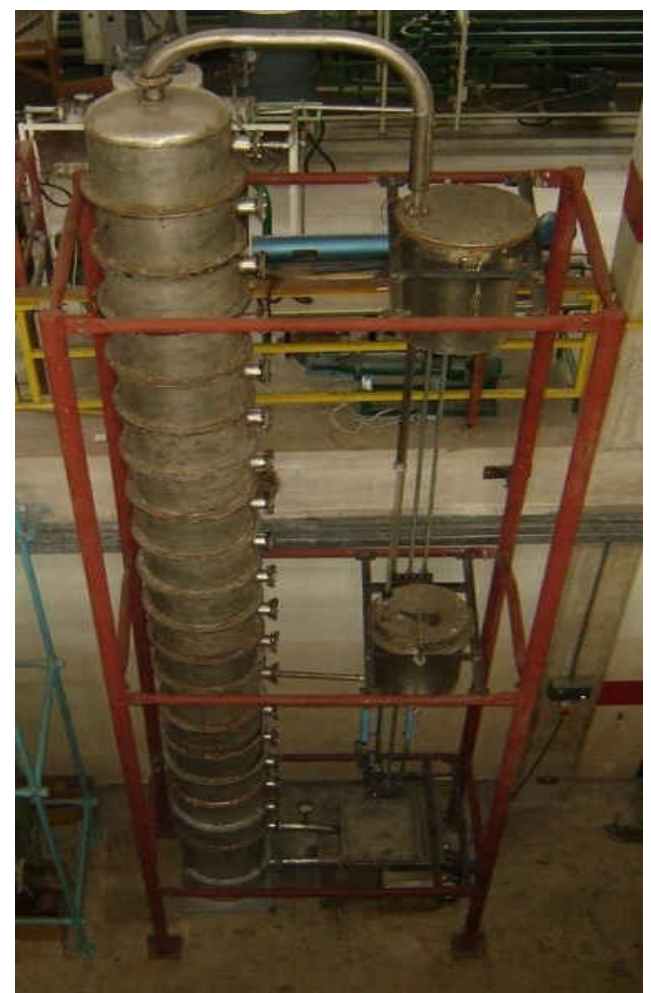

Figure 10: Distillation Column

molasses (see Figure. 2) had already been sterilized using steam. During fermentation the sprouting $\mathrm{CO}_{2}$ was scrubbed through an air lock to keep off oxygen and temperature was maintained at $35{ }^{\circ} \mathrm{C}$ using chilled water at $15{ }^{\circ} \mathrm{C}$ circulating in the cooling coils. Figure 11 shows a decrease of brix from 31.5 to 12.5 during 8 days of fermentation.

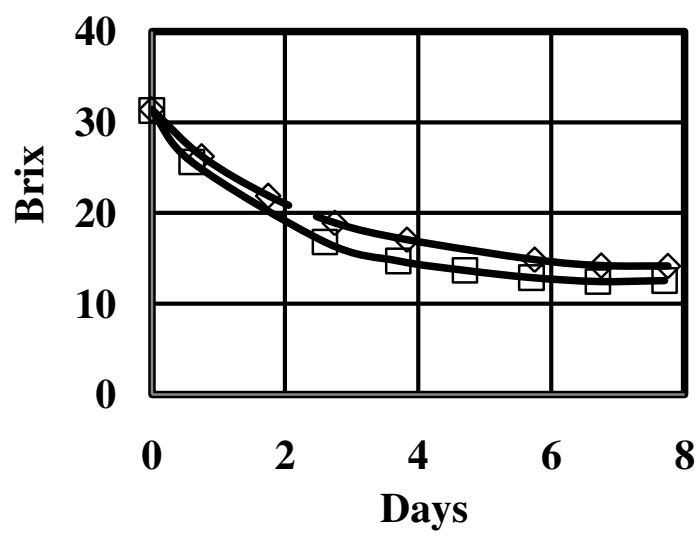

Figure 11: Change of Brix During Fermentation

Figure 12 shows temperature response at different trays T1-T18 and when a batch of 270 liters of mash was heated to $100{ }^{\circ} \mathrm{C}$ in the reboiler TR. Every tray except the reboiler, which is under feedback regulator, exhibited first-order behavior with a time constant of 15-20 minutes and dead-time of 50-65 minutes caused by vapor transport lag that varies depending on tray's distance from the reboiler. Therefore the nominal Laplace domain first-order plant model for tray $n$ can be written as:

$$
T_{n}(s)=\frac{K_{p} e^{-60 s}}{17 s+1} Q(s)
$$

Where $K_{p}$ is the gain associated with the steam rate $\mathrm{Q}(\mathrm{s})$. Although the column is atmospheric, a slight boiling point rise was experienced due to high pressure drop in the condenser when the vapors passed inside tubes and cooling water in outside jacket. This prevented rapid removal of vapor from column and even prevented smooth introduction of feed, which flows by gravity into the column. In view of this the cooling arrangement inside the condenser was reversed by allowing vapor in the jacket and chilled water inside coolingcoils. 


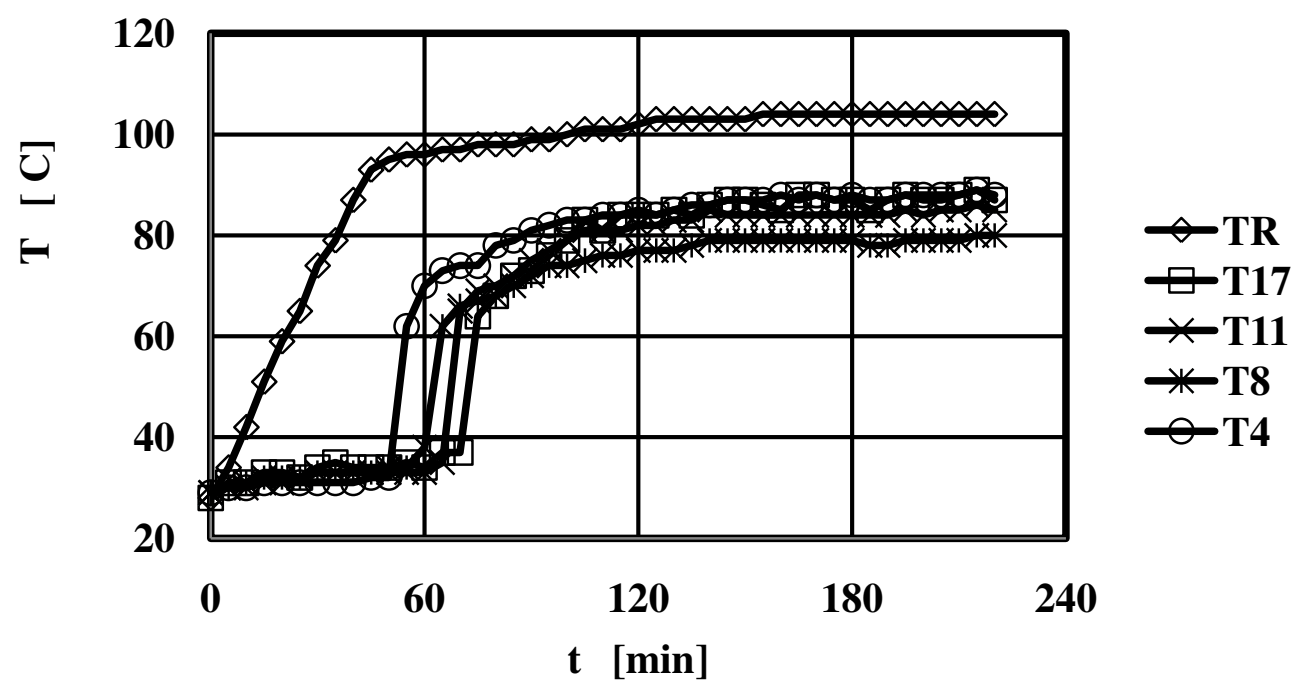

Figure 12: Tray Temperature Response to a Step Change

Figure 13 shows results of batch distillation where ethanol purity dropped from $80 \%$ when vapors starts to form dropping to below $30 \%$ within two hours of operation during which the ethanol content in the still is continuously depleted.

In order to maintain uniform purity of $80 \%$ one needs to conduct continuous distillation under feedback control. This requires computer interface devices, sensors and actuators like control valve, variable speed pump to manipulate the reflux flow rate on-line composition analyzer and a pump. Because these were not available, it was not possible to undertake continuous distillation.

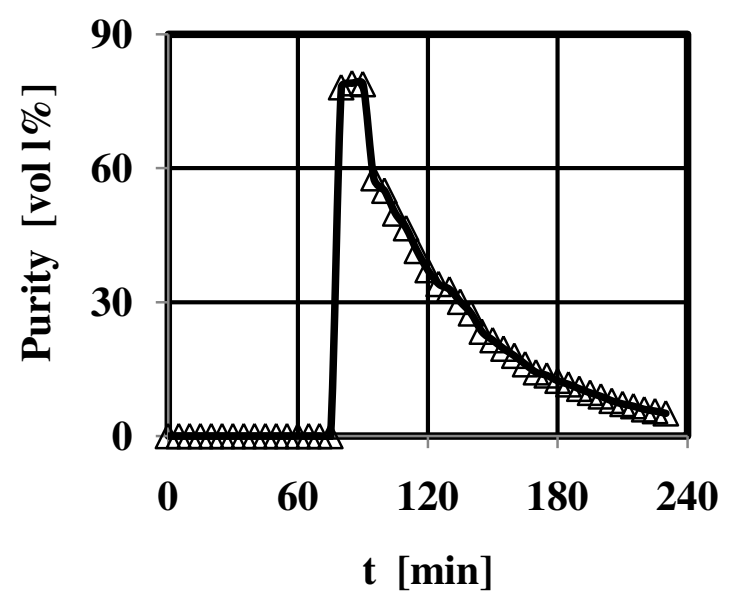

Figure 13: Batch Distillation

\section{CONCLUSIONS AND RECOMMENDATIONS}

A pilot distillation plant has been designed, fabricated, and erected at the Department of Chemical and Mining Engineering. Preliminary tests have been carried out and important issues pertaining to fermentation and distillation have been established, including:

i. A Ms Excel spreadsheet for preparing inoculums recipe for any amount of charge to the fermenter;

ii. A flowchart for preparing dilution of molasses of any brix for feeding in the fermenter; and

iii. Establishment of a dynamic model together with identification of associated parameters like time constant and dead-time.

A total of $200 \mathrm{~L}$ of $50 \%$ ethanol purity was produced under batch distillation but the column could not be fully tested under continuous operation to establish its capacity due to lack of computer interfacing equipment, sensors and actuators like control valves, variable speed pumps, and composition analyzers which will be procured under subsequent project phases. Because composition analyzers like Gas Chromatographs (GC) and on-line refractometers are very expensive, it is recommended to use 
inferential control scheme (Luyben, 1990) where composition is inferred from temperature as shown in Eq. 2. Once completed, the column shall be used as a platform by undergraduate and graduate student to study the production of ethanol from traditional and non-traditional rawmaterials like cassava, cashew fruits, coffee pulp and sisal inulin.

\section{ACKNOWLEDGEMENTS}

The financial support of Sida/SAREC core-support is gratefully acknowledged. The author is also thankful to Dr. K. M. Hosea of the Department of Biotechnology of the University of Dar es Salaam and Ms. Consolota Ngonyani of Sokoine University for help on experimental methods.

\section{REFERENCES}

APCTT-6034TO, (2003), "Industrial Ethanol from Molasses," http: \\www.apctt.org\database \to6034.ht $m l$.

BNDES and CGEE, (2008), SugarcaneBased Bioethanol : Energy for Sustainable Development, Rio de Janeiro, Brazil.

Coulson, J. $\mathrm{M}$ and Richardson, J. F., (1993), Chemical Engineering, Vol. 6, $2^{\text {nd }}$ edition, Pergamon Press Oxford UK.

Elisante, E., (1992), "Robustness and Identification Issues in Horizon Predictive Control with Application to a Binary Distillation Column," MSc Thesis,
Department of Chemical Engineering, Arizona State University.

Fair, J. R., (1961), "How to Predict Sieve Tray Entrainment and Flooding," Petroleum \& Chemical Eng'g, 33, p. 45.

Hatibu, M., (2007), Personal Communication, Msaranga Village, Moshi Municipality, Kilimanjaro Region.

Katalambula, H., Elisante, E. and Mbaruku A.; (1996), De-scaling Sugar Processing Technology in Tanzania," $J$. Science, Technology \& Dev., 14, No. 1.

Kaunde, O. K., (1993), "Design Method for Small Scale Integrated Plants," PhD

Thesis, Department of Chemical Engineering, University of Leeds.

Kibazohi, O., Manyele S. V. and Hosea K., (2003), "Utilization of Sisal: Direct Fermentation of Sisal Inulin to Ethanol," Research Proposal Submitted to Sida/SAREC, Department of Chemical Engineering, University of Dar es Salaam. Mosha, D., Wangabo J. and Mhinzi G., (1996), "African Traditional Brews: How Safe are They?," J. Food Chemistry, 57, No. 2, pp. 205-209.

Saria, J. A., (1999), "African Traditional Brews: Quality, Chemical Constitution and Health Aspects," MSc Thesis, Chemistry Department, Univ. of Dar es Salaam, p.14.

Temu, A. K. and Mbagga J. P., (1993), "Effective Utilization of Sugarcane Molasses for Ethanol Production in Tanzania," J. IET, 5, No. 1, pp. 17-24 